\title{
Is a Cardio-Protective Diet Sustainable? A Review of the Synergies and Tensions Between Foods That Promote the Health of the Heart and the Planet
}

\author{
Shauna M. Downs ${ }^{1}$ - Jessica Fanzo ${ }^{2}$
}

Published online: 2 October 2015

(C) Springer Science+Business Media New York 2015

\begin{abstract}
There are many synergies between a diet that is healthy for the heart and one that is healthy for the planet, but there may also be tensions. We examined the Barilla Center for Food and Nutrition's double pyramid to describe the carbon, water, and ecological footprints of the components of a cardio-protective diet. Overall, fruits, vegetables, and whole grains all tend to have low carbon and water footprints, while nuts and olive oil have relatively higher water footprints and fish have a high ecological footprint. In order to increase the sustainability of a cardio-protective diet, consumers can choose nuts (e.g., walnuts) and oils (e.g., sunflower) with lower water footprints and sustainably produced fish. However, in order to increase consumption of these foods, parallel efforts should be implemented targeting consumer knowledge and incentives to make these foods more affordable.
\end{abstract}

Keywords Cardiovascular disease $\cdot$ Sustainable diets ·

Planetary health $\cdot$ Sustainability

This article is part of the Topical Collection on Cardiovascular Disease

Shauna M. Downs

sd2944@cumc.columbia.edu

Jessica Fanzo

jfanzo@gmail.com

1 Earth Institute and Institute of Human Nutrition, Columbia University, Interchurch Center, Suite 1040, 475 Riverside Drive, New York, NY 10115, USA

2 The Berman Institute of Bioethics and The School of Advanced International Studies, Johns Hopkins University, Washington, DC, USA

\section{Introduction}

Cardiovascular disease (CVD) is the leading cause of death worldwide, accounting for one in four deaths in 2010 [1]. Although in the past, the burden of CVD was largely in high-income countries, approximately three quarters of deaths from CVD now occur in the developing world [2], often at a young age [3]. In 2010, the global cost of CVD was estimated to be US $\$ 863$ billion, and it is projected to rise by $22 \%$ by 2030 [4]. In order to address the burden of CVD, as well as other non-communicable diseases (NCDs), prevention is key. This is particularly important in the developing world, as maternal undernutrition and low birth weight may contribute to an increased risk of CVD for their offspring later in life [5].

Dietary risk factors are a major contributor to the global burden of NCDs such as CVD [6]. By consuming a diet high in fruits and vegetables, whole grains, nuts, vegetable oils, fish and shellfish, and dairy products and consuming less fats and oils containing trans fat, processed meats, sugar sweetened beverages, desserts and bakery foods, and alcohol while maintaining energy balance, CVD risk would decrease [6]. However, the diets of populations worldwide often diverge from a cardio-protective diet. In order to support the consumption of a cardio-protective diet, a shift in the way food is both produced and consumed is necessary.

Our current food system is fractured - the way food is produced (and how it moves through the supply chain) has led to high greenhouse gas (GHG) emissions, depletion of water sources, and biodiversity losses. These environmental changes are linked to anthropogenic (i.e., human) activity [7••]. More specifically, the global production of food is responsible for upward of $30 \%$ of GHG emissions (from food production through to consumption) and more than $70 \%$ of fresh water use (withdrawn from rivers, lakes, and aquifers) [7••]. It is also the largest cause of species biodiversity loss [8]. 
The majority of the GHG emissions in the food system can be attributed to agricultural production [9]. At the same time, agriculture is responsible for a significant amount of blue (surface and groundwater), green (rainwater), and grey (volume of water required to dilute pollutants to the extent that the water quality remains above agreed upon standards) water depletion [10-12]. The agricultural sector accounts for $85 \%$ of the global blue (surface and groundwater) water consumption [13] — one third of the total agriculture-related water footprint can be attributed to the production of animal products, most of which is related to animal feed [11].

There have also been marked changes in biodiversityalthough it has been estimated that 7000 different plant species have been used by humans at one point in time [14•], the world's agricultural landscape is now dominated by only 12 species of grain crops, 23 vegetable crop species, and 35 fruit and nut crops [15]. Moreover, of the 40 livestock species consumed by humans, five species account for $95 \%$ of today's agriculture and food production $[16,17]$.

As the demand for food increases as populations grow and gain wealth to purchase a more varied diet, there will be increased competition for land, water, energy, and other inputs into food production [18••]. The concept of healthy and sustainable diets presents an opportunity to advance commitments to sustainable development and healthy food production and consumption while promoting vibrant agro-ecosystems. The Food and Agriculture Organization [19] has defined sustainable diets as "diets with low environmental impacts which contribute to food and nutrition security and to healthy life for present and future generations. Sustainable diets are protective and respectful of biodiversity and ecosystems, culturally acceptable, accessible, economically fair and affordable; nutritionally adequate, safe and healthy; while optimizing natural and human resources." Although, this definition is comprehensive, it is also complex and difficult to conceptualize what such a diet would look like. Moreover, it suggests that the different components of a sustainable diet are synergistic when, in reality, there will inevitably be trade-offs [20, $21 \bullet \bullet]$.

Several studies in recent years have examined the carbon footprint associated with different dietary patterns [22••, 23•]. Although the reduction in GHG emissions associated with dietary shifts will differ from one context to another, shifting toward a vegan diet will likely elicit the largest reductions in

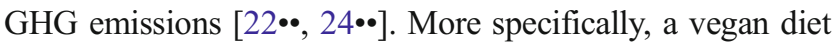
would reduce emissions by between 24 and $53 \%$, a vegetarian diet would result in a GHG emission reduction between 18 and $35 \%$ whereas a Mediterranean diet would result in a reduction between 6 and $17 \%$ [22••]. Although less research has been conducted on the water footprint of food, it is likely that any reduction in animal products - beef in particularwould result in a lower water footprint [10]. These dietary shifts could lead not only to a reduction in GHG emission but also to NCDs such as CVD [24••].

Although overall healthy diets tend to be sustainable [22••], there is some evidence to suggest that there may be a trade-off between health and sustainability [25]. Thus, the objective of this paper was to examine the sustainability of the components of a cardio-protective diet by examining the carbon, water, and ecological footprint of foods that have been associated with a reduced risk of CVD. Although a sustainable diet goes beyond simple carbon and water footprints, the majority of the existing evidence focuses on these aspects of sustainability.

\section{Overview of the Sustainability of a Cardio-Protective Diet}

The components of a cardio-protective diet examined were based on the analysis conducted by Mozaffarian et al. [6]. The carbon, water, and ecological footprints of these components were then examined using data from the Barilla Center for Food and Nutrition for their double pyramid report [26••]. The carbon, water, and ecological footprints were only available for grains and meat more generally rather than for whole grains and processed meats specifically. The Barilla Double Pyramid did not include nuts or alcohol. For that reason, we used values for the carbon footprint from Green et al. [27] and water footprint from Mekonnen and Hoekstra [12]; however, we were unable to examine the ecological footprint of these components of a cardio-protective diet.

The carbon footprint was calculated based on the impact of the production of goods and services throughout the entire life cycle and is expressed in emissions of carbon dioxide equivalents $[26 \bullet \cdot, 28]$. The water footprint was calculated based on the amount of freshwater (green, blue, and grey) used to manufacture a product by totaling the water used at each stage of the production chain $[26 \bullet \bullet, 29]$. The analysis conducted by Mekonnen and Hoekstra was used to ascertain the water footprints of specific fruits, vegetables, nuts, and oils $[12,30]$. The ecological footprint was calculated based on the surface area of land and water that is required for replacing the resources used as well as absorbing the waste in relation to the earth's capacity to regenerate natural resources $[26 \bullet \bullet, 29]$.

Although there are many sources of carbon and water footprint calculations, these tend to be focused on a specific location (e.g., state or country). We chose to use the Barilla Foundation's calculations for the carbon, water, and ecological footprint given that they incorporate values from over 250 sources and are thus more broadly applicable across settings [31]. Moreover, the water footprint calculations conducted by Mekonnen and Hoekstra [12] are average values at the global level rather than being based solely on one region. Although there will be some variability in the carbon and water footprints calculated based on the specific location, there are 
international guidelines for conducting life cycle analyses [28] which increases the comparability of calculations conducted in different contexts.

Figure 1 provides an overview of the carbon, water, and ecological footprints of the different components of a cardioprotective diet as calculated by the Barilla Center for Food and Nutrition for their double pyramid [26••]. Overall, most of the components of a cardio-protective diet have a relatively low carbon, water, and ecological footprint. In terms of foods to encourage, cheese has the highest carbon footprint, while cheese, olive oil, and dried fruit have the highest water footprints. Although fish ${ }^{1}$ has relatively low carbon and water footprints, its ecological footprint is the highest among the components of a cardio-protective whose consumption is encouraged. Regarding the foods to limit, meat - and beef in particular - has the largest carbon, water, and ecological footprint while cookies and sweets tend to have relatively low carbon, water, and ecological footprints. The individual components of a cardio-protective diet and the environmental impact of their production are described in greater detail below.

\section{Energy Balance}

Energy balance is important both in terms of maintaining a healthy body weight and ensuring the sustainability of the food system. Although energy balance on its own may not prevent CVD, reducing portion sizes and weight loss in overweight and obese individuals with diabetes is recommended in order to reduce CVD risk [6, 32-34]. A review of the GHG emissions associated with 16 different dietary patterns found that very high-calorie diets (2400-2800 kcal/capita/day) had higher emissions as compared to lower energy diets (<2100 kcal/capita/day) [35]. Moreover, reducing food consumption in overweight/obese populations has been highlighted as a key area for reducing GHG emissions [9].

\section{Components of a Cardio-Protective Diet: Foods to Encourage}

\section{Fruits, Vegetables, and Nuts}

According to the Global Burden of Disease data, consuming more fruits, vegetables, and nuts would reduce the burden of disease worldwide, largely through reductions in NCDs such as CVD [36]. Although these foods are promoted as a means of reducing the risk of diet-related disease, most populations

\footnotetext{
${ }^{1}$ In the Barilla Double Pyramid, the type of fish (aquaculture versus wild) was not specified. It is important to acknowledge this limitation given that the environmental footprints of wild versus farmed fish can differ markedly.
}

are consuming them in insufficient quantities. From a health perspective, the evidence to support increased consumption is straightforward; however, from a sustainability perspective, it is much more nuanced. Although fruits, vegetables, and nuts tend to have a low carbon footprint, particularly root vegetables (e.g., carrots), tubers (e.g., potatoes), and harder fruits (e.g., apples) [21••], the water footprints of dried fruit, fruit juice, and nuts tend to be larger $[12,26 \bullet \bullet$.

Figure 2 depicts the global average water footprint of various different fruits and vegetables. Overall fruits and vegetables tend to have low water footprints; however, there are marked differences in the water footprint of the different types of fruits and vegetables [12]. For example, avocados, which have a relatively high amount of healthy monounsaturated fat, have a water footprint that is ten times higher than that of carrots and turnips [12]. Although consuming avocados on a regular basis may be beneficial from a CVD perspective [37], increasing their consumption may not be beneficial from an environmental perspective. There are also large variations in the water footprint of different fruits. The global average water footprint of watermelon is over 13 times lower than that of figs [12]. Moreover, dried fruits and fruit juices tend to have a larger water footprint than their non-processed counterparts. For example, fresh apples have a water footprint of $822 \mathrm{~m}^{3} / \mathrm{t}$ as compared to $1141 \mathrm{~m}^{3} / \mathrm{t}$ for apple juice and $6847 \mathrm{~m}^{3} / \mathrm{t}$ for dried apple [12]. Thus, from an environmental perspective, fresh fruit tends to be better than the more processed varieties. It is likely that fresh fruit is more health promoting than processed fruit as well [38], which may be related to the lower fiber content of fruit juice leading to a more rapid, and larger, increase in serum glucose levels after consuming fruit juice as compared to whole fruits [39].

The consumption of nuts has been associated with a reduction in the risk of CVD [6]. However, as compared to fruits and vegetables, there tends to be a larger disconnect between the health and environmental impacts of consuming nuts given their relatively large water footprint. Nevertheless, the water footprint is quite variable for different nut varieties, making it possible to shift consumption toward nuts with lower water footprints while retaining the health benefits of their consumption (Fig. 3). For example, although shelled almonds tend to have a high water footprint, various other nuts including groundnuts (i.e., peanuts) (high in monounsaturated fat) and walnuts (high in omega-3s) have a substantially lower water footprint [12]. However, it is important to recognize that even though the water footprint for nuts (global average $9063 \mathrm{~m}^{3} / \mathrm{t}$ ) can be high, it still remains much lower than for animal products such as beef (global average $15,415 \mathrm{~m}^{3} / \mathrm{t}$ ) [11].

\section{Whole Grains}

Consuming whole grains such as whole grain bread, cooked whole grain rice, pasta, or cereal can reduce the risk of CVD 
Fig. 1 a The water and carbon footprints of the components of a cardio-protective diet. The carbon and water footprints for all foods/ drinks, with the exception of nuts and alcoholic beverages, are from the Barilla Double Pyramid

[26••]. The carbon footprint from Green et al. [27] and water from Mekonnen \& Hoekstra [11, 30] were used for nuts and alcoholic beverages. Carbon footprint: based on the impact of the production of goods and services throughout the entire life cycle and is expressed in emissions of carbon dioxide equivalents [26••, 28]. Water footprint: based on the amount of freshwater (green, blue, and grey) used to manufacture a product by totaling the water used at each stage of the production chain $[26 \bullet \bullet, 29]$. b The ecological footprint of the components of a cardio-protective diet. The ecological footprint for all foods is from the Barilla Double Pyramid [26••].

Ecological footprint: based on the surface area of land and water that is required for replacing the resources used as well as absorbing the waste in relation to the earth's capacity to regenerate natural resources [26••, 29] a

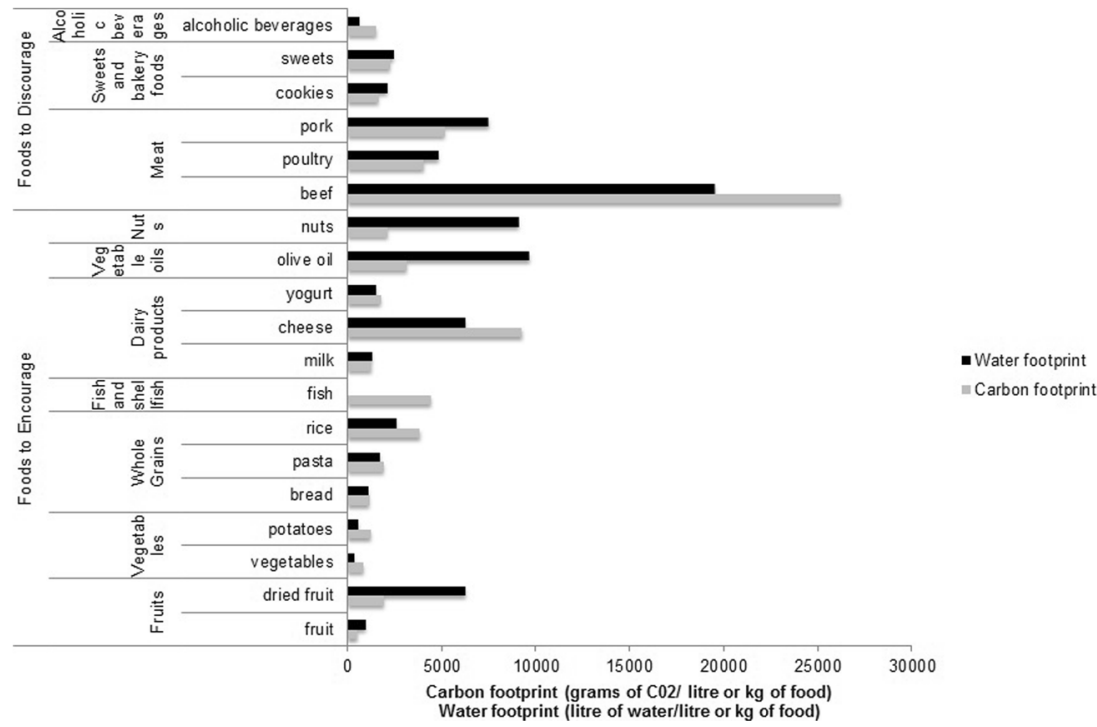

b

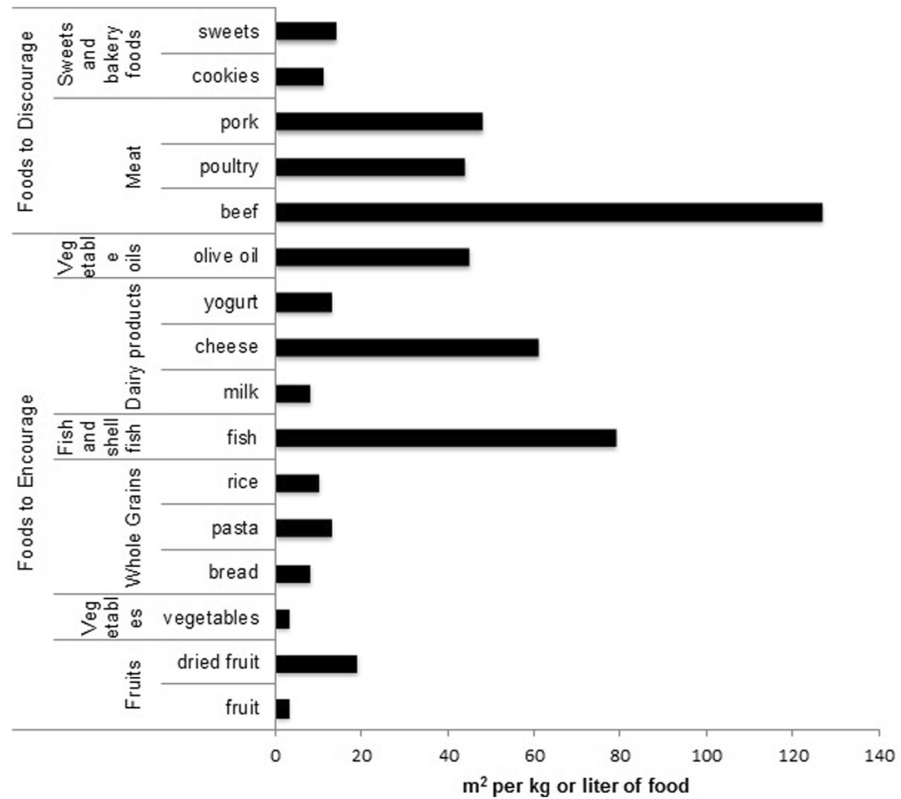

[6]. Although there is a paucity of information about the differences in the environmental impacts of whole versus refined grain, in general, grains tend to have both low carbon and water footprints. Of the grains (rice, pasta, bread) that were examined in the Barilla Double Pyramid, rice had the highest carbon and water footprints, albeit still relatively low. This is due to the way in which rice is produced - it often requires irrigation, and flooded rice fields are a significant source of methane [40]. In fact, it has been estimated that rice production contributes to $10 \%$ of all global agricultural production emissions [8]. This is driven by both the extensive cultivation of rice worldwide and its relatively higher contribution to $\mathrm{GHG}$ emissions as compared to other cereal crops-wheat has one fifth of the GHG emissions as rice per gram of protein $[24 \bullet \bullet]$.

\section{Fish and Shellfish}

Consuming $60 \mathrm{~g} /$ day of fish has been shown to reduce mortality by $12 \%$ [41]. Although the evidence to support the health benefits of fish consumption is strong, there are potential trade-offs between the health benefits and the environmental impact of increasing fish consumption. Although fish do not have a significant carbon footprint, their ecological footprint is relatively high mainly attributed to unsustainable 


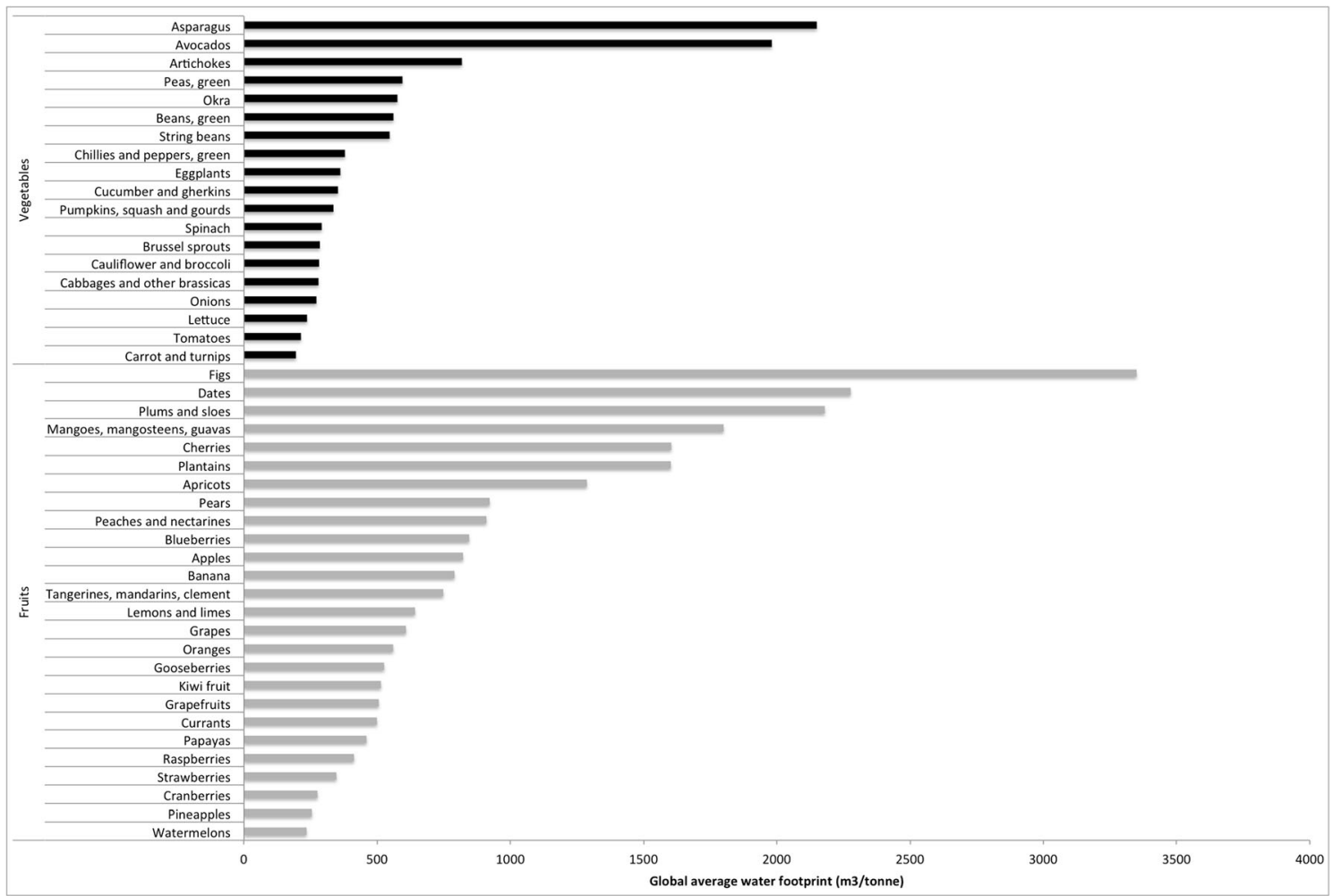

Fig. 2 The global average water footprints of fruits and vegetables. All water footprint values are from Mekonnen \& Hoekstra [11] and include the green, blue, and grey water footprints of crop production which were estimated following the calculation framework of Hoekstra et al. [30]

fishing practices (e.g., overfishing, the use of trawlers, etc.). However, fish is relatively sustainable as compared to terrestrial animals [42].

Concerns have been raised in the past regarding the sustainability of dietary recommendations to increase fish consumption [43]. As both demand and the global population continue to rise worldwide, aquaculture - the world's fastest- growing food production sector-will likely play a bigger role in terms of meeting fish requirements [44]. Fish is one of the most efficient converters of feed into high quality food, and its carbon footprint is lower as compared to other animal production systems [42]. Although, in the past, the fatty acid profile of farmed fish tended to be lower in omega-3s, this has changed with improvements in fish feed. A recent review of
Fig. 3 The global average water footprints of nuts and oils. All water footprint values are from Mekonnen \& Hoekstra [11] and include the green, blue, and grey water footprints of crop production which were estimated following the calculation framework of Hoekstra et al. [30]. Groundnut $=$ peanut

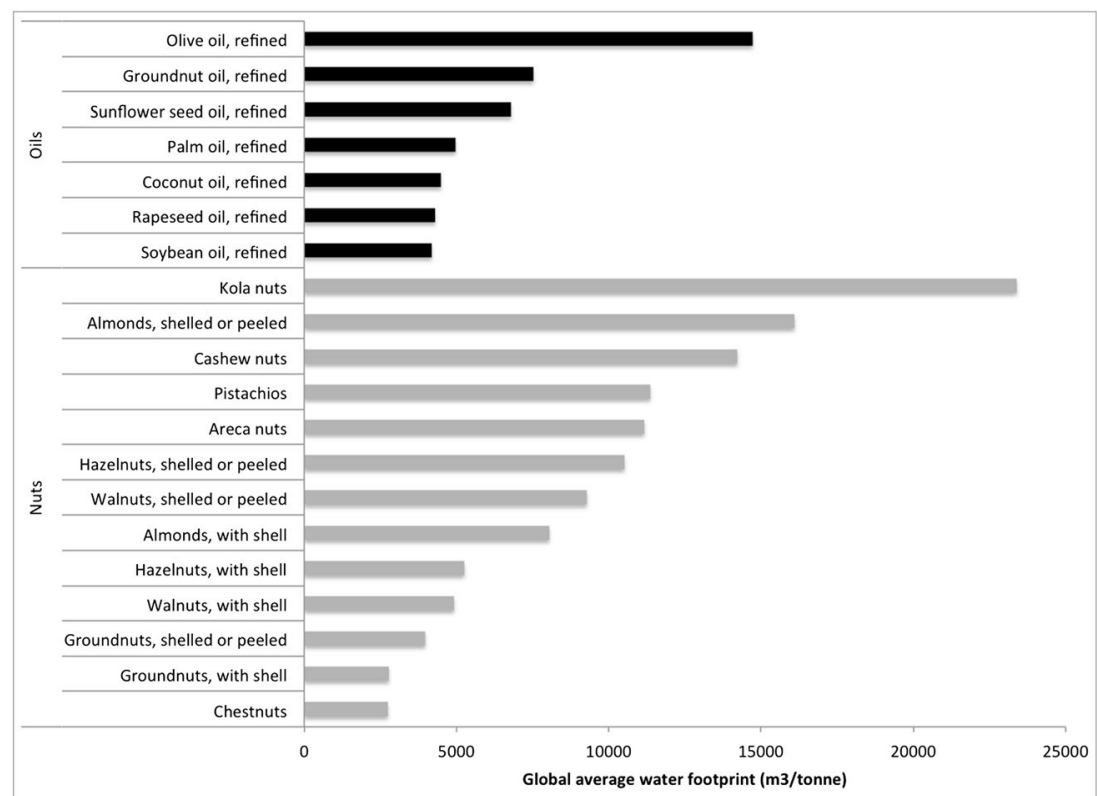


the evidence conducted as part of the US Dietary Guidelines Advisory Committee's report found that for most species that were evaluated, farm-raised seafood had even more omega-3s (which are important for heart health) than their wild counterparts [45]. However, issues remain in terms of use of antibiotics [46] and use of fishmeal for fish feed rather that direct consumption.

\section{Dairy Products}

Milk, yogurt, and cheese all contribute to a cardio-protective diet [6]; however, as with all animal products, the carbon and water footprints of dairy are high. The reason for the high carbon and water footprints of dairy, as well as other animal products, can be attributed to their feed. Moreover, $19 \%$ of the global water footprint of farm animal production can be attributed to dairy cattle [11]. Of the dairy products, cheese has the highest environmental impact given that it takes approximately $10 \mathrm{lb}$ of milk to produce $1 \mathrm{lb}$ of cheese [47]. Shifting toward consumption of milk and yogurt will enable consumers to retain the health benefits of consuming dairy while reducing their environmental footprint.

\section{Vegetable Oils}

Consuming vegetable oils high in polyunsaturated fat (e.g., sunflower, soybean, etc.) can reduce the risk of CVD [6]. Although the evidence regarding the effects of consuming oils high in monounsaturated fat (e.g., groundnut, rapeseed, safflower, olive oil, etc.) on CVD risk is less clear [48], olive oil has been singled out as a heart healthy oil given its central role in the Mediterranean diet. However, olive oil has a relatively high water footprint as compared to other oils high in unsaturated fats such as soybean, rapeseed, sunflower, and groundnut (Fig. 3) [12]. Although demand for olive oil continues to rise [49], from an environmental perspective, it may be beneficial to promote the consumption of other heart healthy oils particularly those high in polyunsaturated fat.

\section{Components of a Cardio-Protective Diet: Foods to Discourage}

\section{Fats, Oils, or Foods Containing or Made with PHO}

Consuming trans fat-ridden partially hydrogenated oils (PHOs) increases the risk of coronary heart disease $[6,50]$. There is no safe limit of trans fat intake, and global recommendations are to limit its intake as low as possible [51]. In fact, the US Food and Drug Administration (FDA) recently ruled to remove the generally recognized as safe (GRAS) status from PHOs. Although the evidence of the health costs of consuming trans fat is clear, there is little to no information on the environmental costs of its consumption. Given that PHOs can be made from various base oils, the environmental footprint will be linked to that of the oil that is used for hydrogenation. One of the oils that has increasingly been used in PHOs - as well as a being a replacement oil when products containing PHOs are reformulated - is palm oil [52-54]. Although the water footprint of palm oil is much lower than olive oil, the ecological footprint is likely to be much higher given the significant amount of deforestation that is taking place to clear land for palm oil plantations which is increasing carbon emissions and leading to losses in biodiversity [55].

\section{Sugar-Sweetened Beverages, Desserts, and Bakery Foods}

Although consuming large amounts of sugar-sweetened beverages, desserts, and bakery foods is not recommended from a health perspective, these foods tend to have relatively low carbon and water footprints. Sugar, one of the most demonized foods from a health perspective, has one of the lowest environmental footprints of all crops [56]. Both sugarcane and sugar beet have lower water footprints than all other food crops, the latter being lower than the former [12].

\section{Processed Meats}

In general, dietary recommendations to reduce CVD include limiting red meat. Lower consumption of red meat, particularly that which is processed, has been consistently shown to be a part of a dietary pattern associated with a lower risk of CVD [6]. From an environmental perspective, meat consumption should be reduced for most populations worldwide, particularly those in high-income countries. Both the carbon and water footprints of beef are the highest of any food item.

The production of $1 \mathrm{~kg}$ of beef protein requires $61.1 \mathrm{~kg}$ of grain as compared to $38 \mathrm{~kg}$ of grain to produce $1 \mathrm{~kg}$ of pork protein and $13.5 \mathrm{~kg}$ to produce $1 \mathrm{~kg}$ of fish [57]. At the same time, $33 \%$ of the global water footprint of farm animal production can be attributed to beef production [11]. Although from a health perspective, the products of grazing animals tend to have an improved nutrient profile given their higher levels of omega-3s, the stearic isomer of saturated fat (rather than myristic and palmitic fatty acids), and vitamins [58], grazing systems have a higher environmental impact as compared to industrial production systems [11, 59]. The higher water and carbon footprint associated with grazing can be attributed to the improved feed conversion efficiencies (about three to four times more feed is required for grazing systems [11]) in industrial production systems and to the higher methane production associated with consumption of grass rather than grain-fed cattle [59]. 


\begin{abstract}
Alcohol
There is a J-shaped relationship between alcohol intake and CVD risk [60]. Recommendations suggest that for those who do drink, women should consume no more than one and men no more than two drinks per day for CVD prevention [6]. There may be an increased risk of other NCDs (e.g., breast cancer) at even lower levels of intake [61]. From an environmental perspective, the carbon and water footprints of alcohol are relatively low but vary based on the type of alcohol - wine tends to be higher than that of beer $[12,62]$ - and its point of origin (i.e., imports). However, if alcohol intake continues to rise, the environmental and health impacts will increase alongside it [63].
\end{abstract}

\section{The Trade-Offs Between Improving Cardiovascular Health and Protecting the Environment}

There are many synergies between a diet that is healthy for the heart and one that is healthy for the planet; however, there are some foods that may have trade-offs in terms of their health benefits and their impact on the environment. More specifically, fish and nuts both have significant benefits from a health perspective but tend to have a large ecological and water footprint, respectively. Moreover, olive oil has a large water footprint and cheese has both large carbon and water footprints. At the same time, consumption of foods such as sweets and bakery products is not beneficial from a health perspective yet has a lower environmental footprint. However, as manufacturers increase the use of palm oil in these productswhich is likely to happen as they reformulate in response to the FDA's ruling - their environmental footprint may increase. Nevertheless, there are choices that can be made in order to reduce the environmental footprint of a cardioprotective diet while retaining the health benefits. For example, consumers can choose to eat nuts, oils, and dairy products with lower carbon and water footprints and can consume fewer calories overall. At the same time, there are also synergies between what is bad for the environment and health; for example, palm oil as well as processed and red meat. However, it is important to note that red meat is an important source of iron and zinc, particularly as a complementary food for infants and young children [64].

\section{Potential Threats to Increasing Consumption of the Components of a Cardio-Protective Diet}

As demand for the foods that are consistent with a cardioprotective diet and the global population increases, production of the components of cardio-protective diet will need to increase as well. However, there are potential threats to increasing production and consumption of these foods. As production increases, it will need to be done sustainably.

Plant biodiversity has declined worldwide which has affected both the number and diversity of species of pollinators [65], which has important implications for the production of fruits, vegetables, nuts, and seeds. Pollinators have been declining worldwide both in managed honey bee colonies as well as in the wild, which is problematic given that they contribute to the yield for an estimated $35 \%$ of global food production [66]. A recent study examining the nutrition and health outcomes associated with a decreased intake of pollinator-dependent foods found that under full pollinator service loss, the average fruit supply would decline by $22.9 \%$, vegetables by $16.3 \%$, and nuts and seeds by $22.1 \%$ [66]. This would subsequently increase the burden of disease associated with NCDs including ischemic heart disease and stroke [66].

There is a need to recognize that many of the foods that promote CVD health are often more costly than those that hinder it, and there has been some evidence to suggest that a sustainable diet is also more costly [67]. Fiscal policies may be needed in order to realign price incentives in order to promote healthy and sustainable diets for all populations, including low-income consumers [68]. For example, governments should invest in research and development into the sustainable production of heart healthy foods. At the consumer level, taxes and subsidies could be used to incentivize consumers to purchase foods that are healthy and sustainable. At the same time, consumer knowledge will need to be increased. For example, seafood watch provides consumers with guidelines on how to choose seafood that has been produced sustainably [69].

\section{Conclusions}

There are many synergies between a diet that is good for the heart and one that is good for the planet, but there are also inconsistencies. Healthy foods are not necessarily sustainable. However, the carbon and water footprints can be quite variable among different foods within the same food group, making it possible to make food choices that are both cardio-protective and have a relatively low environmental impact. In order to promote the consumption of healthier foods that are produced in a sustainable way, production of these foods will need to increase in a way that does not exacerbate already existing strains on the environment. This will necessarily need to be context specific. 
Acknowledgments SMD is supported by a Canadian Institutes of Health Research Postdoctoral Research Fellowship.

\section{Compliance with Ethics Guidelines}

Conflict of Interest Shauna M. Downs and Jessica Fanzo declare that they have no conflict of interest.

Human and Animal Rights and Informed Consent This article does not contain any studies with human or animal subjects performed by any of the authors.

\section{References}

Papers of particular interest, published recently, have been highlighted as:

- Of importance

•. Of major importance

1. Lozano R, Naghavi M, Foreman K, Lim S, Shibuya K, Aboyans V, et al. Global and regional mortality from 235 causes of death for 20 age groups in 1990 and 2010: a systematic analysis for the Global Burden of Disease Study 2010. Lancet. 2012;380:2095-128.

2. World Health Organization. Cardiovascular disease fact sheet, No. 317. Available at: http://www.who.int/mediacentre/factsheets/ fs317/en/

3. Harikrishnan S, Leeder SR, Huffman M, Jeemon P, Prabhakaran D. A race against time: the challenge of cardiovascular diseases in developing economies. Centre for Chronic Disease Control, New Delhi 2015. Available at: http://www.ccdcindia.org/A-RACEAGAINST-TIME.pdf.

4. Bloom DE, Cafiero ET, Jané-Llopis E, Abrahams-Gessel S, Bloom LR, Fathima S, Feigl AB, Gaziano T, Mowafi M, Pandya A, Prettner K, Rosenberg L, Seligman B, Stein, AZ, Weinstein C. The global economic burden of noncommunicable diseases. Geneva: World Economic Forum; 2011. Available at: http://www. weforum.org/reports/global-economic-burden-non-communicablediseases.

5. Adair LS, Prentice AM. A critical evaluation of the fetal origins hypothesis and its implications for developing countries. J Nutr. 2004;134:191-3.

6. Mozaffarian D, Appel LJ, Horn LV. Components of a cardioprotective diet new insights. Circulation. 2011;123:2870-91.

7.•• Whitmee S, Haines A, Beyrer C, Boltz F, Capon AG, de Souza Dias $\mathrm{BF}$, et al. The Rockefeller Foundation-Lancet Commission on planetary health. Safeguarding human health in the Anthropocene epoch: report of The Rockefeller Foundation-Lancet Commission on planetary health. Lancet. 2015 . This paper provides a comprehensive overview of the inextricable link between planetary and human health in the age of the anthropocene.

8. World Resource Institute. Creating a sustainable food future: a menu of solutions to sustainably feed more than 9 billion people by 2050. Washington, DC 2014. Available at: CreatingSustainableFoodFuture.pdf

9. Garnett T. Where are the best opportunities for reducing greenhouse gas emissions in the food system (including the food chain)? Food Policy. 2011;36(Supplement 1):S23-32.

10. Hoekstra AY. Water for animal products: a blind spot in water policy. Environ Res Lett. 2014;9:091003.

11. Mekonnen M, Hoekstra A. A global assessment of the water footprint of farm animal products. Ecosystems. 2012;15:401-15.
12. Mekonnen MM, Hoekstra AY. The green, blue and grey water footprint of crops and derived crop products. Hydrol Earth Syst Sci. 2011;15:1577-600.

13. Shiklomanov IA. World water resources: a new appraisal and assessment for the 21st century. St Petersburg, Russia 1998. Available at: 112671Eo.pdf

14. World Health Organization. Connecting global priorities: biodiversity and human health. Geneva, Switzerland 2015. Available at: https://www.bioversityinternational.org/e-library/publications/ detail/connecting-global-priorities-biodiversity-and-human-health/. This report provides an overview of the links between biodiversity conservation and losses and human health.

15. Fowler C, Mooney PR. The threatened gene: food, politics and the loss of genetic diversity. Cambridge; 1990.

16. Heywood, V. Overview of agricultural biodiversity and its contribution to nutrition and health. diversifying food and diets: using agricultural biodiversity to improve nutrition and health. New York, NY. 2013;35-67.

17. Rischkowsky B, Pilling D. The state of the world's animal genetic resources for food and agriculture. Food \& Agriculture Organisation; 2007. Available at: http://www.fao.org/docrep/010/ a1250e/a1250e00.HTM.

18.• Garnett T, Appleby MC, Balmford A, Bateman IJ, Benton TG, Bloomer P, et al. Sustainable intensification in agriculture: premises and policies. Science. 2013;341:33-4. This paper discusses sustainable intensification and some of the policy implications of producing more food using fewer resources.

19. Torres CPR. Sustainable diets and biodiversity: directions and solutions for policy, research and action. Future Food J Food Agric Soc. 2013;1(2):131-3.

20. Johnston JL, Fanzo JC, Cogill B. Understanding sustainable diets: a descriptive analysis of the determinants and processes that influence diets and their impact on health, food security, and environmental sustainability. Adv Nutr Int Rev J. 2014;5:418-29. This paper was one of the first to describe the determinants of a healthy and sustainable diet.

21.• Garnett T. What is a sustainable healthy diet? A discussion paper. Oxford, United Kingdom: Food Climate Research Network ( F C R N ); 2014 . A v a i l a b l e a t : fcrn_what_is_a_sustainable_healthy_diet_final.pdf. This report describes the components of a sustainable healthy diet.

22.• Hallström E, Carlsson-Kanyama A, Börjesson P. Environmental impact of dietary change: a systematic review. J Clean Prod. 2015;91:1-11. This paper is a systematic review of the environmental impact of shifting dietary patterns towards a lower intake of animal products.

23. Auestad N, Fulgoni VL. What current literature tells us about sustainable diets: emerging research linking dietary patterns, environmental sustainability, and economics. Adv Nutr Int Rev J. 2015;6: 19-36. This paper reviews the existing literature on healthy and sustainable diet.

24.• Tilman D, Clark M. Global diets link environmental sustainability and human health. Nature. 2014;515:518-22. This paper examines the environmental impact of different dietary patterns in the context of increased demand for animal products and global population growth.

25. Vieux F, Soler L-G, Touazi D, Darmon N. High nutritional quality is not associated with low greenhouse gas emissions in self-selected diets of French adults. Am J Clin Nutr. 2013; ajen.035105.

26.• Barilla Center for Food \& Nutrition. Double Pyramid 2015: recommendations for a sustainable diet. Rome, Italy; 2015. Available at: http://www.barillacfn.com/en/position-paper/pp-double-pyramid2015-recommendations-for-a-sustainable-diet/. This report analyzes the carbon, water and ecological footprints of a healthy and sustainable diet. 
27. Green R, Milner J, Dangour AD, Haines A, Chalabi Z, Markandya $A$, et al. The potential to reduce greenhouse gas emissions in the UK through healthy and realistic dietary change. Clim Chang. 2015;129:253-65.

28. International Organization for Standardization. Greenhouse gases - carbon footprint of products - requirements and guidelines for quantification and communication (ISO/TS 14067). 2013. Available at: http://www.iso.org/iso/iso_catalogue/catalogue tc/ catalogue_detail.htm?csnumber $=59521$.

29. Water footprint Network. Global Water Footprint Standard. 2015. Available at: http://waterfootprint.org/en/standard/global-waterfootprint-standard/

30. Hoekstra AY, Chpagain AK, Aldaya MM, Mekonnen MM. The water footprint assessment manual: setting the global standard. London, UK; 2011. Available at: TheWaterFootprintAssessmentManual_2.pdf

31. Ruini LF, Ciati R, Pratesi CA, Marino M, Principato L, Vannuzzi E. Working toward healthy and sustainable diets: the "double pyramid model" developed by the Barilla Center for Food and Nutrition to Raise Awareness about the Environmental and Nutritional Impact of Foods. Front Nutr. 2015;2.

32. Kumanyika SK, Obarzanek E, Stettler N, Bell R, Field AE, Fortmann SP, et al. Population-based prevention of obesity the need for comprehensive promotion of healthful eating, physical activity, and energy balance: a scientific statement from American Heart Association Council on Epidemiology and Prevention, Interdisciplinary Committee for Prevention (Formerly the Expert Panel on Population and Prevention Science). Circulation. 2008;118:428-64

33. Fox CS, Golden SH, Anderson C, Bray GA, Burke LE, de Boer IH, et al. Update on prevention of cardiovascular disease in adults with type 2 diabetes mellitus in light of recent evidence a scientific statement from the American Heart Association and the American Diabetes Association. Circulation. 2015;132:691-718.

34. Wing RR, Lang W, Wadden TA, Safford M, Knowler WC, Bertoni AG, et al. Benefits of modest weight loss in improving cardiovascular risk factors in overweight and obese individuals with type 2 diabetes. Diabetes Care. 2011;34:1481-6.

35. Pradhan P, Reusser DE, Kropp JP. Embodied greenhouse gas emissions in diets. PLoS ONE. 2013;8.

36. Lim SS, Vos T, Flaxman AD, Danaei G, Shibuya K, Adair-Rohani $\mathrm{H}$, et al. A comparative risk assessment of burden of disease and injury attributable to 67 risk factors and risk factor clusters in 21 regions, 1990-2010: a systematic analysis for the Global Burden of Disease Study 2010. Lancet. 2012;380:2224-60.

37. Dreher ML, Davenport AJ. Hass avocado composition and potential health effects. Crit Rev Food Sci Nutr. 2013;53:738-50.

38. Muraki I, Imamura F, Manson JE, Hu FB, Willett WC, van Dam RM, et al. Fruit consumption and risk of type 2 diabetes: results from three prospective longitudinal cohort studies. BMJ. 2013;347: f5001.

39. Bolton RP, Heaton KW, Burroughs LF. The role of dietary fiber in satiety, glucose, and insulin: studies with fruit and fruit juice. Am J Clin Nutr. 1981;34:211-7.

40. Intergovernmental Panel on Climate Change. IPCC Special Report: land use, land-use change and forestry. 2000. Available at: http:// www.ipcc.ch/ipccreports/sres/land use/index.php?idp=228.

41. Zhao L-G, Sun J-W, Yang Y, Ma X, Wang Y-Y, Xiang Y-B. Fish consumption and all-cause mortality: a meta-analysis of cohort studies. Eur J Clin Nutr. 2015,

42. Béné C, Barange M, Subasinghe R, Pinstrup-Andersen P, Merino G, Hemre G-I, et al. Feeding 9 billion by 2050 - putting fish back on the menu. Food Secur. 2015;7:261-74.

43. Jenkins DJA, Sievenpiper JL, Pauly D, Sumaila UR, Kendall CWC, Mowat FM. Are dietary recommendations for the use of fish oils sustainable? Can Med Assoc J. 2009;180:633-7.
44. High Level Panel of Experts. Sustainable fisheries and aquaculture for food security and nutrition. A report by the High Level Panel of Experts on Food Security and Nutrition of the Committee on World Food Security, Romel; 2014. Available at: Sustainable fisheries and aquaculture for food security and nutrition - a-i3844e.pdf.

45. The 2015 Dietary Guidelines Advisory Committee. Scientific Report of the 2015 Dietary Guidelines Advisory Committee. Washington DC; 2015. Available at: http://www.health.gov/ dietaryguidelines/2015-scientific-report/.

46. Romero J, Feijoó CG, Navarrete P. Antibiotics in aquaculture - use, abuse and alternatives. INTECH Open Access Publisher; 2012. Available at: Antibiotics in Aquaculture.pdf.

47. Environmental Resources Center, University of Wisconsin Extension. Understanding the carbon footprint of cheese. Cooperative Extension Publishing; 2011. Available at: http:// clean-water.uwex.edu/pubs/pdf/CF-Cheese.pdf.

48. Schwingshackl L, Hoffmann G. Monounsaturated fatty acids and risk of cardiovascular disease: synopsis of the evidence available from systematic reviews and meta-analyses. Nutrients. 2012;4(12): 1989-2007.

49. Xiong B, Sumner D, Matthews W. A new market for an old food: the US demand for olive oil. Agric Econ. 2014;45(S1):10718.

50. Mozaffarian D, Clarke R. Quantitative effects on cardiovascular risk factors and coronary heart disease risk of replacing partially hydrogenated vegetable oils with other fats and oils. Eur J Clin Nutr. 2009;63 Suppl 2:S22-33.

51. Uauy R, Aro A, Clarke R, Ghafoorunissa, L'Abbé MR, Mozaffarian D, et al. WHO Scientific Update on trans fatty acids: summary and conclusions. Eur J Clin Nutr. 2009;63:S68-75.

52. Hooker N, Downs S. Trans-border reformulation: US and Canadian Experiences with trans fat. Int Food Agribus Manag Rev. 2014;17(A).

53. Downs SM, Gupta V, Ghosh-Jerath S, Lock K, Thow AM, Singh A. Reformulating partially hydrogenated vegetable oils to maximise health gains in India: is it feasible and will it meet consumer demand? BMC Public Health. 2013;13:1139.

54. Unnevehr LJ, Jagmanaite E. Getting rid of trans fats in the US diet: policies, incentives and progress. Food Policy. 2008;33:497-503.

55. Fitzherbert EB, Struebig MJ, Morel A, Danielsen F, Brühl CA, Donald PF, et al. How will oil palm expansion affect biodiversity? Trends Ecol Evol. 2008;23:538-45.

56. Drewnowski A. Healthy diets for a healthy planet. Am J Clin Nutr. 2014;99:1284-5.

57. Hall SJ. Blue frontiers: managing the environmental costs of aquaculture. WorldFish. 2011. Available at: http://www.conservation. org/publications/Pages/blue_frontiers_aquaculture.aspx.

58. Daley CA, Abbott A, Doyle PS, Nader GA, Larson S. A review of fatty acid profiles and antioxidant content in grass-fed and grain-fed beef. Nutr J. 2010;9:10.

59. Bailey R, Harper DR. Reviewing interventions for healthy and sustainable diets. Chatham House, UK; 2015. Available at: http:// www.chathamhouse.org/sites/files/chathamhouse/field/field document/20150529HealthySustainableDietsBaileyHarper_0.pdf.

60. Emberson JR, Bennett DA. Effect of alcohol on risk of coronary heart disease and stroke: causality, bias, or a bit of both? Vasc Health Risk Manag. 2006;2:239-49.

61. Key J, Hodgson S, Omar RZ, Jensen TK, Thompson SG, Boobis AR, et al. Meta-analysis of studies of alcohol and breast cancer with consideration of the methodological issues. Cancer Causes Control. 2006;17:759-70.

62. Berners-Lee M, Hoolohan C, Cammack H, Hewitt CN. The relative greenhouse gas impacts of realistic dietary choices. Energy Policy. 2012;43:184-90. 
63. Garnett T. The alcohol we drink and its contribution to the UK's greenhouse gas emissions: a discussion paper. Centre for Environmental Strategy, University of Surrey, UK; 2007. Available at: http://www. fcrn.org.uk/sites/default/files/ALCOHOL $\% 20$ final $\% 20$ version $\%$ 20TG\%20feb\%202007.pdf.

64. World Health Organization. Global strategy for infant and young child feeding. Geneva, Switzerland; 2003. Available at: http://www. who.int/nutrition/publications/infantfeeding/9241562218/en/.

65. Potts SG, Biesmeijer JC, Kremen C, Neumann P, Schweiger O, Kunin WE. Global pollinator declines: trends, impacts and drivers. Trends Ecol Evol. 2010;25:345-53.

66. Smith MR, Singh GM, Mozaffarian D, Myers SS. Effects of decreases of animal pollinators on human nutrition and global health: a modelling analysis. Lancet. 2015.
67. Barosh L, Friel S, Engelhardt K, Chan L. The cost of a healthy and sustainable diet-who can afford it? Aust N Z J Public Health. 2014;38:7-12.

68. Garnett T, Mathewson S, Angelides P and Borthwick F. Policies and actions to shift eating patterns: what works? A review of the evidence of the effectiveness of interventions aimed at shifting diets in more sustainable and healthy directions. Food Climate Research Network, University of Oxford; 2015. Available at: http://www. fcrn.org.uk/fcrn-publications/reports/policies-and-actions-shifteating-patterns-what-works.

69. Seafood Watch. Printable consumer guides with seafood and sushi recommendations from the Seafood Watch Program at the Monterey Bay Aquarium. available at: http://www.seafoodwatch. org/seafood-recommendations/consumer-guides 